\title{
ANALISIS ANGGARAN BIAYA KESELAMATAN DAN KESEHATAN KERJA PROYEK KONSTRUKSI GEDUNG SMA N 2 ABIANSEMAL
}

\author{
Ni Putu Indah Yuliana ${ }^{1)}$ dan Ni Kadek Sri Ebtha Yuni ${ }^{1)}$ \\ 1) Jurusan Teknik Sipil, Politeknik Negeri Bali, Badung, Bali \\ putuindah3107@pnb.ac.id
}

\begin{abstract}
One of the efforts made by construction service companies to minimize accident rates is to implement an occupational safety and health management system (OSHMS) for construction. The construction service provider must provide costs for OSH requirements taken from the total project cost. This research has a certain purpose that is to find out the amount of occupational safety and health costs needed as well as the comparison between regulations and the field. The study was conducted in the form of surveys and interviews where the data analysis stage is to compile a list of risks that occur, risk assessment, risk mitigation, calculate OSH costs with the price of the store survey and SE No. 11/SE/M/2019 (SE19) prices and calculate the percentage of OSH costs to the contract. The results showed 22 accident and safety risks identified with 14 low category risks and 8 medium category risks. The OSH cost required based on the price of the field unit is IDR. 402,142,520.00, while the fee based on SE19 is IDR. 359,005,000.00. The OSH costs field prices are greater than OSH costs SE19 with a difference of 0.08\% or IDR. 43,137,520.00.
\end{abstract}

Keywords: construction services, risk identification, risk assessment, OSH costs

\begin{abstract}
ABSTRAK
Salah satu upaya yang dilakukan oleh perusahaan jasa konstruksi untuk meminimalkan angka kecelakaan adalah melaksanakan sistem manajemen keselamatan dan kesehatan kerja (SMK3) konstruksi. Penyedia jasa konstruksi harus menyediakan biaya untuk keperluan K3 yang diambil dari total biaya proyek. Penelitian ini memiliki tujuan yaitu agar dapat diketahui besaran biaya keselamatan dan kesehatan kerja yang diperlukan juga perbandingannya antara peraturan dan lapangan. Penelitian dilaksanakan dalam bentuk survey dan wawancara dimana tahapan analisis data adalah menyusun daftar risiko yang terjadi, menilai risiko, mitigasi risiko, melakukan perhitungan biaya K3 dengan harga hasil survey toko dan harga Surat Edaran Nomor 11/SE/M/2019 (SE19) dan menghitung persentase biaya K3 terhadap kontrak. Hasil penelitian menunjukkan teridentifikasi 22 risiko kecelakaan dan keselamatan kerja dengan 14 risiko kategori rendah dan 8 risiko kategori sedang. Biaya K3 yang diperlukan bersadarkan harga satuan lapangan adalah sebesar Rp. 402,142,520.00 sedangkan biaya berdasarkan peraturan SE19 adalah Rp. 359,005,000.00. Biaya K3 harga lapangan lebih besar daripada biaya K3 harga SE19 dengan selisih 0.08\% atau sebesar Rp. 43,137,520.00.
\end{abstract}

Kata kunci: jasa konstruksi, identifikasi risiko, penilaian risiko, biaya K3 


\section{PENDAHULUAN}

\subsection{Latar Belakang}

Indonesia adalah negara berkembang yang sedang giat melaksanakan pembangunan infrastruktur penunjang di segala bidang. Salah satu pembangunan infrastruktur yang banyak dilakukan adalah pembangunan di bidang konstruksi, baik itu jalan raya, gedung, bangunan air dan lain sebagainya. Bidang konstruksi merupakan penyumbang terbanyak dalam angka kecelakaan kerja baik di Indonesia maupun di dunia. Angka kecelakaan yang terjadi di Indonesia adalah 123,041 kasus di tahun 2017 dan 173,105 kasus di tahun 2018 dengan total klaim yang dibayarkan Rp 1.2 triliun (BPJS, 2019).

Dalam setiap pelaksanaan proyek konstruksi, tentunya semua pihak yang terlibat didalamnya berharap tidak terjadi kecelakaan kerja (zero accident) sehingga keberhasilan proyek dapat tercapai selain dari segi waktu, mutu dan biaya. Salah satu upaya yang dilakukan oleh perusahaan jasa konstruksi untuk meminimalkan angka kecelakaan adalah melaksanakan sistem manajemen keselamatan dan kesehatan kerja (SMK3) konstruksi. Penyedia jasa konstruksi harus menyediakan biaya untuk keperluan K3 yang diambil dari total biaya proyek meskipun biaya tersebut masuk kategori biaya umum dan tidak spesifik tercantum dalam kontrak (Ananti, 2019). Hal ini sesuai dengan amanat SE Menteri PUPR No 11 Tahun 2019 yang mengatur tentang petunjuk teknis biaya penyelenggaraaan sistem manajemen keselamatan konstruksi.

Penelitian terkait pembiayaan K3 di bidang konstruksi telah banyak dilakukan dan menghasilkan persentase biaya yang berbeda-beda dari setiap proyek yang menjadi tinjauan penelitian. Hal ini sejalan dengan sifat proyek yaitu unik dimana tidak ada proyek yang identik dan hanya ada proyek yang sejenis. Hasil penelitian tentang Estimasi Biaya Pencegahan dan Pengawasan K3 pada Proyek Konstruksi menyatakan biaya yang diperlukan untuk pencegahan dan pengawasan proyek adalah Rp 726,182,726.28 atau 5.39\% dari total nilai kontrak (Jawat \& Suwitanuwijaya, 2018). Penelitian tentang Analisis Biaya Keselamatan dan Kesehatan Kerja (K3) pada Proyek Konstruksi juga menghasilkan biaya K3 yang diperlukan sebesar $1.85 \%$ dari nilai kontrak (Ananti, 2019).

Proyek pembangunan Gedung SMA $\mathrm{N} 2$ Abiansemal adalah proyek yang dikerjakan untuk menunjang pelaksanaan pendidikan di Kabupaten Badung, Provinsi Bali. Proyek ini mencakup pembangunan 3 (tiga) unit gedung belajar, 1 (satu) 
basement dan prasarana penunjang lainnya dimana semua ini rencana dilaksanakan selama 230 (dua ratus tiga puluh) hari kalender. Waktu yang terbatas dan lingkup pekerjaan yang luas akan menimbulkan resiko-resiko kecelakaan yang berakibat pada kebutuhan Alat Pelindung Diri (APD) dan bermuara ke kebutuhan biaya untuk K3 proyek.

\subsection{Rumusan Masalah}

1. Berapakah biaya keselamatan dan kesehatan kerja yang diperlukan untuk pembangunan proyek pembangunan SMA N 2 Abiansemal berdasarkan peraturan dan lapangan?

2. Bagaimanakah perbandingan biaya keselamatan dan kesehatan kerja antara peraturan dan lapangan?

\subsection{Tujuan}

1. Mengetahui besaran biaya keselamatan dan kesehatan kerja yang diperlukan untuk pembangunan proyek pembangunan SMA $\mathrm{N} 2$ Abiansemal berdasarkan peraturan dan lapangan.

2. Mengetahui perbandingan biaya keselamatan dan kesehatan kerja antara peraturan dan lapangan.

\subsection{Batasan Penelitian}

1. Risiko K3 yang terjadi dalam pelaksanan proyek diidentifikasi secara umum untuk semua tahapan pelaksanaan pekerjaan untuk selanjutnya dinilai dan ditentukan mitigasinya.

2. Analisis rencana biaya K3 ditinjau dari SE Menteri PUPR No 11 Tahun 2019 dan harga toko untuk kemudian diperbandingkan dengan nilai kontrak.

\section{KAJIAN PUSTAKA}

\subsection{Keselamatan dan Kesehatan Kerja} (K3)

Pengertian keselamatan dan kesehatan kerja (K3) menurut filosofi Mangkunegara adalah upaya yang dilakukan untuk memberikan jaminan kepada tenaga kerja agar keutuhan dan kesempurnaan jasmani dan rohani mereka tetap terjaga sehingga bisa tercapai tujuan masyarakat yang adil dan Makmur. Sedangkan menurut OHSAS 18001:2017, keselamatan dan kesehatan kerja (K3) adalah seluruh situasi dan penyebab yang dapat memberikan dampak terhadap keselamatan dan kesehatan kerja para tenaga kerja di lokasi kerja masing-masing (Djatmiko, 2016). 


\subsection{Sistem Manajemen Keselamatan dan Kesehatan Kerja (SMK3)}

Menurut Peraturan Menteri Tenaga Kerja No 5 Tahun 1996, sistem manajemen keselamatan dan kesehatan kerja (SMK3) adalah keseluruhan bagian sistem manajemen yang meliputi susunan organisasi, perencanaan, tanggung jawab, pelaksanaan, tata cara, proses dan sumber daya yang diperlukan untuk pengembangan, penerapan, pencapaian, pengkajian dan pemeliharaan kebijakan keselamatan dan kesehatan kerja untuk mengendalikan risiko yang berkaitan dengan kegiatan kerja sehingga dapat tercipta lingkungan kerja yang aman, efisien dan produktif. Adapun elemenelemen yang menjadi pedoman dalam penerapan SMK3 di Indonesia menurut Peraturan Menteri Tenaga Kerja No 5 Tahun 1996 adalah komitmen dan kebijakan, perencanaan, penerapan, pengukuran dan evaluasi juga tinjauan ulang dan peningkatan.

\subsection{Identifikasi Bahaya/ Risiko (Hazard/ Risk)}

Hazard (bahaya) adalah semua kondisi dan tindakan yang memiliki kemungkinan untuk menyebabkan terjadinya kecelakaan, kerusakan atau cedera pada manusia. Identifikasi hazard dilakukan untuk mengetahui, mengenal dan memperkirakan risiko yang mungkin terjadi pada sistem operasi, peralatan, prosedur dan unit kerja. Hazard atau risiko yang telah diidentifikasi selanjutnya dianalisis nilai tingkat keparahannya untuk kemudian dilakukan pengendalian terhadap bahaya yang teridentifikasi (Jawat \& Suwitanuwijaya, 2018).

\subsection{Penilaian Risiko (Risk Assessment)}

Penilaian risiko adalah proses memberikan perhitungan terhadap risiko hasil identifikasi (Norken, 2015). Dalam penilaian risiko $\mathrm{K} 3$, tingkat kekerapan (frekuensi) dikalikan dengan tingkat keparahan (konsekuensi) (Jawat \& Suwitanuwijaya, 2018). Hasil perkalian selanjutnya dihubungkan dengan nilai risiko sehingga dapat ditentukan prioritas dari risiko yang telah dinilai. Adapun tingkat kekerapan, keparahan dan jenis prioritas penilaian risiko $\mathrm{K} 3$ ditunjukkan dalam Tabel 1, Tabel 2 dan Tabel 3.

\section{Tabel 1. Tingkat Kekerapan (Frekuensi)}

\begin{tabular}{cl}
\hline Nilai & \multicolumn{1}{c}{ Keterangan } \\
\hline 1 & $\begin{array}{l}\text { Kejadian termasuk belum pernah } \\
\text { terjadi dalam pelaksanaan proyek }\end{array}$ \\
2 & $\begin{array}{l}\text { Kejadian termasuk jarang terjadi dalam } \\
\text { pelaksanaan proyek } \\
3\end{array}$ \\
& $\begin{array}{l}\text { Kejadian termasuk kadang-kadang } \\
\text { terjadi dalam pelaksanaan proyek } \\
\text { Kejadian termasuk sering terjadi dalam } \\
\text { pelaksanaan proyek } \\
\text { Kejadian termasuk sangat sering terjadi } \\
\text { dalam pelaksanaan proyek }\end{array}$ \\
\hline
\end{tabular}

Sumber: PT. Hutama Karya dalam Sucita, 2011 
Tabel 2. Tingkat Keparahan (Konsekuensi)

\begin{tabular}{|c|c|c|c|}
\hline Nilai & Tipe Luka & Tipe Sakit & $\begin{array}{c}\text { Kerugian } \\
(\mathrm{Rp})\end{array}$ \\
\hline 1 & Tanpa luka & Tidak sakit & $\begin{array}{c}\text { Kurang dari } \\
1 \text { juta }\end{array}$ \\
\hline 2 & $\begin{array}{l}\text { Pengobatan } \\
\text { P3K }\end{array}$ & $\begin{array}{l}\text { Sakit } \\
\text { ringan }\end{array}$ & $\begin{array}{c}\text { Antara } 1 \\
\text { sampai } 10 \\
\text { juta }\end{array}$ \\
\hline 3 & $\begin{array}{l}\text { Rawat } \\
\text { jalan }\end{array}$ & $\begin{array}{l}\text { Sakit } \\
\text { sedang }\end{array}$ & $\begin{array}{c}\text { Lebih dari } 10 \\
\text { juta sampai } \\
500 \text { juta }\end{array}$ \\
\hline 4 & Rawat inap & Sakit berat & $\begin{array}{l}\text { Lebih dari } \\
500 \text { juta } \\
\text { sampai } 1 \\
\text { milyar }\end{array}$ \\
\hline 5 & $\begin{array}{l}\text { Meninggal } \\
\text { dunia }\end{array}$ & $\begin{array}{l}\text { Cacat } \\
\text { permanen }\end{array}$ & $\begin{array}{c}\text { Lebih dari } 1 \\
\text { milyar }\end{array}$ \\
\hline
\end{tabular}

Tabel 3. Jenis Prioritas

\begin{tabular}{cccccc}
\hline $\begin{array}{c}\text { Frek } \\
\text { uensi }\end{array}$ & 1 & 2 & 3 & 4 & 5 \\
\hline & 1 & 2 & 3 & 4 & 5 \\
1 & Risiko & Risiko & Risiko & Risiko & Risiko \\
& rendah & rendah & rendah & rendah & sedang \\
& 2 & 4 & 6 & 8 & 10 \\
2 & Risiko & Risiko & Risiko & Risiko & Risiko \\
& rendah & rendah & sedang & sedang & sedang \\
& 3 & 6 & 9 & 12 & 15 \\
3 & Risiko & Risiko & Risiko & Risiko & Risiko \\
& rendah & sedang & sedang & tinggi & tinggi \\
& 4 & 8 & 12 & 16 & 20 \\
4 & Risiko & Risiko & Risiko & Risiko & Risiko \\
& rendah & sedang & tinggi & tinggi & tinggi \\
& 5 & 10 & 15 & 20 & 25 \\
5 & Risiko & Risiko & Risiko & Risiko & Risiko \\
& sedang & sedang & tinggi & tinggi & tinggi \\
\hline
\end{tabular}

Sumber: PT. Hutama Karya dalam Sucita, 2011

\subsection{Perencanaan Biaya Keselamatan dan Kesehatan Kerja (K3)}

Perencanaan biaya keselamatan dan kesehatan kerja (K3) untuk proyek konstruksi sangat penting untuk dilaksanakan agar nantinya pelaksanaan konstruksi proyek berjalan dengan lancar dan tidak mengalami hambatan. Besaran biaya K3 bisa berbeda-beda antara tiap proyek tergantung pada besar kecilnya proyek yang akan dilaksanakan, lokasi proyek, jenis proyek dan potensi bahaya yang mungkin ditimbulkan (Ananti, 2019). Pemerintah Indonesia melalui Kementerian Pekerjaan Umum dan Perumahan Rakyat telah mengeluarkan Surat Edaran Nomor 11/SE/M/2019 yang mengatur tentang petunjuk teknis biaya penyelenggaraaan sistem manajemen keselamatan konstruksi. Adapun rincian kegiatan penyelenggaraan SMK3 Konstruksi diantaranya:

1. Penyiapan RKK

2. Sosialisasi dan Promosi K3

3. Alat Pelindung Kerja

4. Alat Pelindung Diri

5. Asuransi dan Perijinan

6. Personil K3 Konstruksi

7. Fasilitas, sarana, prasarana, alat kesehatan

8. Rambu-rambu

9. Konsultasi Ahli

10. Lain-lain terkait Pengendalian Risiko

\section{METODE PERENCANAAN}

\subsection{Rancangan Penelitian}

Penelitian dilaksanakan dalam bentuk survey dan wawancara untuk memperoleh data-data yang diperlukan dalam analisis. Survey dilakukan untuk mencari rincian harga peralatan $\mathrm{K} 3$ dan wawancara dilakukan untuk menentukan 
risiko-risiko yang terjadi selama masa pelaksanaan proyek. Wawancara dilakukan dengan personil K3 proyek dan site manager proyek. Analisis data menggunakan bantuan Microsoft Excel dengan memasukkan semua komponen yang akan dianalisis.

\subsection{Penentuan Sumber Data}

Data yang digunakan untuk penelitian ada 2 (dua) jenis data yaitu data primer dan data sekunder. Data primer dalam penelitian ini diperoleh dari survey harga di toko yang berada dekat dengan lokasi proyek juga hasil wawancara dengan personil K3 proyek serta pengamatan langsung di lapangan. Sedangkan data sekunder yang digunakan yaitu studi terdahulu, Rencana Anggaran Biaya (RAB) proyek, daftar analisa pekerjaan dan time schedule.

\subsection{Analisis Data}

\subsubsection{Menyusun daftar risiko kecelakaan dan kesehatan kerja yang terjadi}

Penyusunan daftar risiko dilakukan dengan pengamatan langsung di lapangan dan wawancara dengan personil K3 proyek dan site manager proyek.

\subsubsection{Melakukan penilaian risiko $\mathrm{K} 3$}

Penilaian dilakukan untuk risikorisiko yang telah teridentifikasi agar dapat ditentukan prioritas risikonya. Penilaian dilakukan dengan mengalikan nilai tingkat kekerapan dengan nilai tingkat keparahan untuk selanjutnya ditentukan kategori prioritas risiko.

\subsubsection{Menentukan tindakan mitigasi untuk risiko $\mathrm{K} 3$}

Penentuan tindakan mitigasi dilakukan untuk risiko-risiko K3 yang telah teridentifikasi dan dinilai. Tindakan mitigasi ditentukan dengan wawancara kepada personil $\mathrm{K} 3$ proyek dan site manager proyek.

\subsubsection{Melakukan perhitungan biaya K3}

Perhitungan dilakukan dengan mengalikan volume masing-masing biaya penyiapan alat pelindung diri (APD) dan kelengkapan K3 dengan harga per masingmasing item tersebut sehingga diperoleh biaya masing-masing kegiatan penyelenggaran K3. Biaya tersebut selanjutnya dijumlahkan sehingga diketahui besar biaya total yang diperlukan untuk pelaksanaan K3. Perhitungan dilakukan dua kali yaitu dengan harga hasil survey toko dan harga sesuai Surat Edaran Nomor 11/SE/M/2019.

\subsubsection{Melakukan perhitungan persentase biaya K3 terhadap kontrak \\ Perhitungan biaya K3 yang telah dilakukan selanjutnya ditentukan persentase dengan nilai kontrak keseluruhan pekerjaan.}




\section{HASIL DAN PEMBAHASAN}

\subsection{Identifikasi Risiko K3}

Identifikasi terhadap risiko kejadian keselamatan dan kesehatan kerja selama pelaksanaan proyek dilakukan melalui wawancara dengan personil K3 proyek dan site manager. Selain itu, dilakukan pengamatan lapangan untuk melihat risikorisiko yang mungkin terjadi akibat pelaksanaan pekerjaan. Adapun risiko yang teridentifikasi dalam pelaksanaan proyek ditunjukkan dalam Tabel 4.

\section{Tabel 4. Identifikasi Risiko K3}

\begin{tabular}{cl}
\hline No & \multicolumn{1}{c}{ Identifikasi Risiko } \\
\hline 1 & Kemasukan debu \\
2 & Pingsan akibat terik sinar matahari \\
3 & Tertimbun tanah \\
4 & Terjatuh ke lubang \\
5 & Excavator terperosok ke lubang \\
6 & Tergores besi \\
7 & Tertusuk besi \\
8 & Terjatuh dari skafolding saat merakit besi \\
9 & Terluka akibat kena paku atau palu dan \\
& gergaji \\
10 & Material terjatuh dan menimpa pekerja \\
11 & Gangguan pernapasan \\
12 & Terjatuh dari ketinggian \\
13 & Terluka akibat alat manual \\
14 & Terpercik bahan kimia \\
15 & Terluka saat perakitan atap baja ringan \\
16 & Terpeleset \\
17 & Terperosok ke lubang besi \\
18 & Tersandung kabel vibrator \\
19 & Tersengat listrik \\
20 & Keracunan akibat menghirup bahan kimia \\
21 & Terpercik api las \\
22 & Iritasi kulit \\
\hline
\end{tabular}

\subsection{Penilaian Risiko K3}

Risiko-risiko yang telah teridentifikasi selanjutnya dinilai dengan mengalikan antara tingkat kekerapan dengan tingkat keparahan yang terjadi.
Penilaian risiko dilakukan oleh site manager dan personil K3 proyek. Hasil penilaian dari 22 risiko yang teridentifikasi, 8 risiko termasuk kategori prioritas sedang dan 14 risiko lainnya masuk kategori risiko prioritas rendah. Adapun hasil penilaian risiko ditunjukkan dalam Tabel 5.

Tabel 5. Penilaian Risiko K3

\begin{tabular}{|c|c|c|c|}
\hline No & Identifikasi Risiko & $\begin{array}{c}\text { Nilai } \\
\text { Risiko }\end{array}$ & Keterangan \\
\hline 1 & Kemasukan debu & 4 & Risiko rendah \\
\hline 2 & $\begin{array}{l}\text { Pingsan akibat } \\
\text { terik sinar matahari }\end{array}$ & 1 & Risiko rendah \\
\hline 3 & Tertimbun tanah & 2 & Risiko rendah \\
\hline 4 & Terjatuh ke lubang & 2 & Risiko rendah \\
\hline 5 & $\begin{array}{l}\text { Excavator } \\
\text { terperosok ke } \\
\text { lubang }\end{array}$ & 3 & Risiko rendah \\
\hline 6 & $\begin{array}{l}\text { Terjatuh dari } \\
\text { ketinggian }\end{array}$ & 4 & Risiko rendah \\
\hline 7 & $\begin{array}{l}\text { Terpercik bahan } \\
\text { kimia }\end{array}$ & 3 & Risiko rendah \\
\hline 8 & Terpeleset & 4 & Risiko rendah \\
\hline 9 & $\begin{array}{l}\text { Terperosok ke } \\
\text { lubang besi }\end{array}$ & 2 & Risiko rendah \\
\hline 10 & $\begin{array}{l}\text { Tersandung kabel } \\
\text { vibrator }\end{array}$ & 4 & Risiko rendah \\
\hline 11 & Tersengat listrik & 4 & Risiko rendah \\
\hline 12 & $\begin{array}{l}\text { Keracunan akibat } \\
\text { menghirup bahan } \\
\text { kimia }\end{array}$ & 4 & Risiko rendah \\
\hline 13 & Terpercik api las & 4 & Risiko rendah \\
\hline 14 & Iritasi kulit & 2 & Risiko rendah \\
\hline 15 & Tergores besi & 6 & Risiko sedang \\
\hline 16 & $\begin{array}{l}\text { Tertusuk besi } \\
\text { Terjatuh dari }\end{array}$ & 6 & Risiko sedang \\
\hline 17 & $\begin{array}{l}\text { skafolding saat } \\
\text { merakit besi } \\
\text { Terluka akibat }\end{array}$ & 3 & Risiko sedang \\
\hline 18 & $\begin{array}{l}\text { kena paku atau } \\
\text { palu dan gergaji }\end{array}$ & 4 & Risiko sedang \\
\hline 19 & $\begin{array}{l}\text { Material terjatuh } \\
\text { dan menimpa } \\
\text { pekerja }\end{array}$ & 6 & Risiko sedang \\
\hline 20 & $\begin{array}{l}\text { Gangguan } \\
\text { pernapasan }\end{array}$ & 6 & Risiko sedang \\
\hline 21 & $\begin{array}{l}\text { Terluka akibat alat } \\
\text { manual }\end{array}$ & 6 & Risiko sedang \\
\hline 22 & $\begin{array}{l}\text { Terluka saat } \\
\text { perakitan atap baja } \\
\text { ringan }\end{array}$ & 6 & Risiko sedang \\
\hline
\end{tabular}


Berdasarkan Tabel 5, dilakukan tindakan mitigasi/pengendalian terhadap risiko yang teridentifikasi. Pengendalian risiko diperoleh melalui wawancara dengan personil K3 dan site manager. Dari wawancara, mitigasi yang dilakukan terhadap risiko yang teridentifikasi adalah pada Tabel 6.

\section{Tabel 6. Mitigasi Risiko K3}

\begin{tabular}{|c|c|c|}
\hline No & Identifikasi Risiko & Mitigasi \\
\hline 1 & Kemasukan debu & $\begin{array}{l}\text { APD (masker, kaca mata } \\
\text { pelindung) }\end{array}$ \\
\hline 2 & $\begin{array}{l}\text { Pingsan akibat terik } \\
\text { sinar matahari }\end{array}$ & Menyediakan air minum \\
\hline 3 & Tertimbun tanah & $\begin{array}{l}\text { APK (pagar pembatas, } \\
\text { rambu) }\end{array}$ \\
\hline 4 & Terjatuh ke lubang & $\begin{array}{l}\text { APK (pagar pembatas, } \\
\text { rambu) }\end{array}$ \\
\hline 5 & $\begin{array}{l}\text { Excavator terperosok } \\
\text { ke lubang }\end{array}$ & $\begin{array}{l}\text { APK (pagar pembatas, } \\
\text { rambu) }\end{array}$ \\
\hline 6 & $\begin{array}{l}\text { Terjatuh dari } \\
\text { ketinggian }\end{array}$ & $\begin{array}{l}\text { APK (jaring pengaman), } \\
\text { APD (safety belt) }\end{array}$ \\
\hline 7 & $\begin{array}{l}\text { Terpercik bahan } \\
\text { kimia }\end{array}$ & Tools box meeting \\
\hline 8 & Terpeleset & $\begin{array}{l}\text { APK (jaring pengaman), } \\
\text { APD (safety belt) }\end{array}$ \\
\hline 9 & $\begin{array}{l}\text { Terperosok ke } \\
\text { lubang besi }\end{array}$ & $\begin{array}{l}\text { APK (pagar pembatas, } \\
\text { rambu) }\end{array}$ \\
\hline 10 & $\begin{array}{l}\text { Tersandung kabel } \\
\text { vibrator }\end{array}$ & $\begin{array}{l}\text { APK (pagar pembatas, } \\
\text { rambu) }\end{array}$ \\
\hline 11 & Tersengat listrik & $\begin{array}{l}\text { APK (pagar pembatas, } \\
\text { rambu), APD (sepatu) }\end{array}$ \\
\hline 12 & $\begin{array}{l}\text { Keracunan akibat } \\
\text { menghirup bahan } \\
\text { kimia }\end{array}$ & APD (masker) \\
\hline 13 & Terpercik api las & $\begin{array}{l}\text { APD (kaca mata } \\
\text { pengaman) }\end{array}$ \\
\hline 14 & Iritasi kulit & Tools box meeting \\
\hline 15 & Tergores besi & Tools box meeting \\
\hline 16 & Tertusuk besi & APD (sarung tangan) \\
\hline 17 & $\begin{array}{l}\text { Terjatuh dari } \\
\text { skafolding saat } \\
\text { merakit besi }\end{array}$ & $\begin{array}{l}\text { APK (jaring pengaman), } \\
\text { APD (safety belt) }\end{array}$ \\
\hline 18 & $\begin{array}{l}\text { Terluka akibat kena } \\
\text { paku atau palu dan } \\
\text { gergaji }\end{array}$ & APD (sarung tangan) \\
\hline 19 & $\begin{array}{l}\text { Material terjatuh dan } \\
\text { menimpa pekerja }\end{array}$ & $\begin{array}{l}\text { APD (sarung tangan, } \\
\text { helm) }\end{array}$ \\
\hline 20 & $\begin{array}{l}\text { Gangguan } \\
\text { pernapasan }\end{array}$ & APD (masker) \\
\hline 21 & $\begin{array}{l}\text { Terluka akibat alat } \\
\text { manual }\end{array}$ & $\begin{array}{l}\text { APD (sarung tangan, } \\
\text { helm, sepatu, masker) }\end{array}$ \\
\hline 22 & $\begin{array}{l}\text { Terluka saat } \\
\text { perakitan atap baja } \\
\text { ringan }\end{array}$ & $\begin{array}{l}\text { APK (jaring pengaman), } \\
\text { APD (safety belt, sarung } \\
\text { tangan, sepatu) }\end{array}$ \\
\hline
\end{tabular}

Tindakan mitigasi dilakukan dengan melakukan eliminasi terhadap risiko yang mungkin terjadi, TBM (tools box meeting), menyediakan APK dan APD. Tindakan mitigasi ini menjadi pertimbangan dalam menyusun analisis biaya K3.

\subsection{Perhitungan Biaya Keselamatan dan Kesehatan Kerja (K3)}

Berdasarkan hasil mitigasi risiko $\mathrm{K} 3$, dilakukan perencanaan keperluan biaya untuk mitigasi risiko mengikuti ketentuan yang ada dalam SE No. 11/SE/M/2019. Namun tidak semua ketentuan dalam surat edaran yang masuk kedalam perhitungan biaya K3 karena perhitungan biaya disesuaikan dengan hasil identifikasi dan penilaian risiko. Perhitungan biaya K3 didasarkan pada 2 (dua) sumber harga yaitu berdasarkan harga lapangan yang diperoleh melalui survei dan harga berdasarkan SE No. 11/SE/M/2019.

\subsubsection{Perhitungan biaya K3 dengan harga lapangan \\ Berdasarkan hasil wawancara} dengan site manager proyek, jumlah pekerja lapangan yang terlibat dalam pelaksanaan proyek berjumlah 75 orang. Selain itu, staff yang terlibat ada 15 orang. Perhitungan ini memerlukan daftar harga yang diperoleh melalui survei di toko yang berada dekat lokasi pekerjaan. Adapun hasil perhitungan ditunjukkan dalam Tabel 7. 
Tabel 7. Perhitungan Biaya K3 Harga Lapangan

\begin{tabular}{rlr}
\hline No & \multicolumn{1}{c}{ Uraian } & \multicolumn{1}{c}{ Jumlah } \\
Harga (Rp)
\end{tabular}

\begin{tabular}{|c|c|c|}
\hline No & Uraian & $\begin{array}{c}\text { Jumlah } \\
\text { Harga (Rp) }\end{array}$ \\
\hline VIII & Rambu-rambu & \\
\hline 1 & Rambu petunjuk & $500,000.00$ \\
\hline 2 & Rambu larangan & $500,000.00$ \\
\hline 3 & Rambu peringatan & $500,000.00$ \\
\hline 4 & Rambu kewajiban & $500,000.00$ \\
\hline 5 & Rambu informasi & $300,000.00$ \\
\hline 6 & $\begin{array}{l}\text { Rambu pekerjaan } \\
\text { sementara }\end{array}$ & $300,000.00$ \\
\hline 7 & $\begin{array}{l}\text { Tongkat pengatur lalu } \\
\text { lintas }\end{array}$ & $150,000.00$ \\
\hline 8 & Kerucut lalu lintas & $500,000.00$ \\
\hline 9 & Jalur evakuasi & $500,000.00$ \\
\hline IX & \multicolumn{2}{|c|}{$\begin{array}{l}\text { Lain-lain terkait pengendalian risiko } \\
\text { K3 }\end{array}$} \\
\hline 1 & $\begin{array}{l}\text { Pembuatan Kartu } \\
\text { Identitas Pekerja (KIP) }\end{array}$ & $525,000.00$ \\
\hline 2 & $\begin{array}{l}\text { Alat pemadam api } \\
\text { ringan (APAR) }\end{array}$ & $1,750,000.00$ \\
\hline 3 & Bendera K3 & $100,000.00$ \\
\hline 4 & Sirine & $200,000.00$ \\
\hline & TOTAL & $402,142,520.00$ \\
\hline
\end{tabular}

\subsubsection{Perhitungan Biaya K3 dengan SE Nomor 11/SE/M/2019}

Perhitungan dilakukan dengan cara yang sama dengan perhitungan biaya berdasarkan harga lapangan, namun harga satuan diubah sesuai dengan harga satuan yang ada di SE Nomor 11/SE/M/2019. Hasil perhitungan dapat dilihat di Tabel 8.

Tabel 8. Perhitungan Biaya K3 Harga SE Nomor 11/SE/M/2019

\begin{tabular}{clr}
\hline No & \multicolumn{1}{c}{ Uraian } & $\begin{array}{c}\text { Jumlah Harga } \\
\text { (Rp) }\end{array}$ \\
\hline I & Penyiapan RK3K & \\
& Pembuatan Manual, \\
1 & $\begin{array}{l}\text { Prosedur, Instruksi } \\
\text { II }\end{array}$ & $5,000,000.00$ \\
II & Kerja, Ijin Kerja & Sosialisasi dan Promosi K3 \\
& Induksi K3 (khusus & \\
1 & untuk pekerja baru) & $562,500.00$ \\
2 & Simulasi K3 & $562,500.00$ \\
3 & Spanduk & $450,000.00$ \\
4 & Poster & $150,000.00$ \\
5 & Papan Informasi K3 & $1,000,000.00$ \\
III & Alat Pelindung Kerja & \\
1 & Jaring Pengaman & $15,000,000.00$ \\
2 & Tali Keselamatan & $5,000,000.00$ \\
3 & Penahan Jatuh & $15,000,000.00$ \\
\hline
\end{tabular}




\begin{tabular}{|c|c|c|}
\hline No & Uraian & $\begin{array}{l}\text { Jumlah Harga } \\
\text { (Rp) }\end{array}$ \\
\hline 4 & Pelindung jatuh & $1,000,000.00$ \\
\hline IV & Alat Pelindung Diri & \\
\hline 1 & Topi pelindung & $6,750,000.00$ \\
\hline 2 & $\begin{array}{l}\text { Pelindung pernafasan } \\
\text { dan mulut }\end{array}$ & $14,400,000.00$ \\
\hline 3 & Sarung tangan & $1,350,000.00$ \\
\hline 4 & $\begin{array}{l}\text { Sepatu keselamatan } \\
\text { untuk staff }\end{array}$ & $5,250,000.00$ \\
\hline 5 & Sepatu keselamatan & $26,250,000.00$ \\
\hline 6 & Rompi keselamatan & $2,250,000.00$ \\
\hline 7 & Pelindung mata & $375,000.00$ \\
\hline 8 & $\begin{array}{l}\text { Tameng wajah untuk } \\
\text { pekerja las }\end{array}$ & $3,000,000.00$ \\
\hline $\mathbf{V}$ & $\begin{array}{l}\text { Asuransi dan Perijinan } \\
\text { BPJS }\end{array}$ & \\
\hline 1 & $\begin{array}{l}\text { Ketenagakerjaan dan } \\
\text { Kesehatan Kerja }\end{array}$ & $21,940,000.00$ \\
\hline 2 & $\begin{array}{l}\text { Surat ijin kelaikan } \\
\text { Alat }\end{array}$ & $8,500,000.00$ \\
\hline 3 & $\begin{array}{l}\text { Surat ijin operator } \\
\text { Surat ijin pengesahan } \\
\text { panitia pembina }\end{array}$ & $6,500,000.00$ \\
\hline 4 & $\begin{array}{l}\text { keselamatan dan } \\
\text { kesehatan kerja } \\
(\mathrm{P} 2 \mathrm{~K} 3)\end{array}$ & $1,000,000.00$ \\
\hline VI & Personil K3 & \\
\hline 1 & Ahli K3 & $80,000,000.00$ \\
\hline 2 & $\begin{array}{l}\text { Petugas K3 } \\
\text { Asst. Petugas }\end{array}$ & $64,000,000.00$ \\
\hline 3 & $\begin{array}{l}\text { K3/Safety } \\
\text { Man/Pengatur Lalu } \\
\text { Lintas }\end{array}$ & $64,000,000.00$ \\
\hline VII & $\begin{array}{l}\text { Fasilitas Sarana Keseha } \\
\text { Peralatan K3 (Kotak }\end{array}$ & $\tan$ \\
\hline 1 & $\begin{array}{l}\text { P3k, Tandu, Tabung } \\
\text { Oksigen, Obat Luka, } \\
\text { Perban, Dll) }\end{array}$ & $1,500,000.00$ \\
\hline 2 & $\begin{array}{l}\text { Peralatan Pengasapan } \\
\text { (Fogging) }\end{array}$ & $500,000.00$ \\
\hline 3 & Obat Pengasapan & $90,000.00$ \\
\hline 4 & Bak sampah & $750,000.00$ \\
\hline VIII & Rambu-rambu & \\
\hline 1 & Rambu petunjuk & $375,000.00$ \\
\hline 2 & Rambu larangan & $375,000.00$ \\
\hline 3 & Rambu peringatan & $375,000.00$ \\
\hline 4 & Rambu kewajiban & $375,000.00$ \\
\hline 5 & Rambu informasi & $225,000.00$ \\
\hline 6 & $\begin{array}{l}\text { Rambu pekerjaan } \\
\text { sementara }\end{array}$ & $225,000.00$ \\
\hline 7 & $\begin{array}{l}\text { Tongkat pengatur } \\
\text { lalu lintas }\end{array}$ & $150,000.00$ \\
\hline 8 & Kerucut lalu lintas & $500,000.00$ \\
\hline 9 & Jalur evakuasi & $500,000.00$ \\
\hline IX & $\begin{array}{l}\text { Lain-lain terkait pengen } \\
\text { K3 }\end{array}$ & ndalian risiko \\
\hline 1 & Pembuatan Kartu & $525,000.00$ \\
\hline
\end{tabular}

\begin{tabular}{|c|c|c|}
\hline No & Uraian & $\begin{array}{c}\text { Jumlah Harga } \\
\text { (Rp) }\end{array}$ \\
\hline & $\begin{array}{l}\text { Identitas Pekerja } \\
\text { (KIP) }\end{array}$ & \\
\hline 2 & $\begin{array}{l}\text { Alat pemadam api } \\
\text { ringan (APAR) }\end{array}$ & $2,750,000.00$ \\
\hline 3 & Bendera K3 & $300,000.00$ \\
\hline 4 & Sirine & $200,000.00$ \\
\hline & TOTAL & $359,005,000.00$ \\
\hline
\end{tabular}

\subsection{Perbandingan Biaya K3 dengan Nilai Kontrak}

Dari hasil perhitungan biaya K3 berdasarkan harga lapangan dan SE Nomor 11/SE/M/2019, selanjutnya dilakukan perbandingan persentase biaya-biaya tersebut dengan nilai kontrak proyek. Nilai kontrak yang dipakai adalah nilai kontrak tanpa PPN (Pajak Penambahan Nilai) 10\%. Adapun hasil perhitungan ditunjukkan dalam Tabel 9.

Tabel 9. Perhitungan Biaya K3 Harga SE Nomor 11/SE/M/2019

\begin{tabular}{clrc}
\hline No & \multicolumn{1}{c}{ Uraian } & Nilai ( Rp. x1000) & $\%$ \\
\hline 1 & $\begin{array}{l}\text { RAB tanpa PPN } \\
10 \%\end{array}$ & $51,284,628.46$ & 0.00 \\
2 & $\begin{array}{l}\text { Biaya K3 Harga } \\
\text { Lapangan }\end{array}$ & $402,142.52$ & 0.78 \\
3 & $\begin{array}{l}\text { Biaya K3 SE No } \\
\text { 11SE/M/2019 }\end{array}$ & $359,005.00$ & 0.70 \\
\hline
\end{tabular}

Berdasarkan hasil analisa perbandingan dan persentase biaya $\mathrm{K} 3$, dapat dilihat bahwa persentase biaya K3 harga lapangan sedikit lebih besar daripada persentase biaya K3 harga SE No. 11/SE/M/2019 dengan selisih 0.08\%, dimana hal ini disebabkan oleh karena harga satuan lapangan adalah harga terkini dibandingkan dengan harga yang tercantum dalam SE No. 11/SE/M/2019. 


\section{SIMPULAN DAN SARAN}

\subsection{Simpulan}

1. Biaya K3 yang diperlukan berdasarkan harga satuan lapangan adaah sebesar $\mathrm{Rp}$. 402,142,520.00 sedangkan biaya berdasarkan peraturan SE No. 11/SE/M/2019 adalah Rp. $359,005,000.00$.

2. Perbandingan biaya K3 antara harga lapangan dengan harga dalam peraturan adalah persentase biaya K3 harga lapangan lebih besar daripada persentase biaya K3 harga SE No. 11/SE/M/2019 dengan selisih $0.08 \%$ atau sebesar Rp. 43,137,520.00.

\subsection{Saran}

1. Diperlukan penelitian lebih lanjut terkait rencana anggaran biaya K3 di proyek pembangunan gedung SMA yang berbeda sehingga dapat diperoleh kisaran biaya rencana K3 untuk proyek pembangunan gedung SMA.

2. Diperlukan analisis lebih lanjut untuk perbandingan antara rencana biaya $\mathrm{K} 3$ dengan aktualisasinya di lapangan.

\section{DAFTAR PUSTAKA}

Ananti, G. A. (2019). Analisis Biaya Keselamatan dan Kesehatan Kerja (K3) pada Proyek Konstruksi (Studi Kasus: Pembangunan Gedung Lt. II SD N 13 Kesiman. Seminar Nasional Keteknisipilan Bidang Vokasional VII, 247-251. Bali: Jurusan Teknik Sipil Politeknik Negeri Bali.

BPJS. (2019). BPJS Ketenagakerjaan. Retrieved January 16, 2019, from https://www.bpjsketenagakerjaan.go. $\mathrm{id} /$ berita/23322/Angka-KecelakaanKerja-Cender

Djatmiko. (2016). Keselamatan dan Kesehatan Kerja. Yogyakarta: Deepublish.

Jawat, I. W., \& Suwitanuwijaya, I. N. (2018). Estimasi Biaya Pencegahan dan Pengawasan K3 pada Proyek Konstruksi. PADURAKSA, 7(1), 88101.

Norken, I. N. (2015). Pengantar Analisis dan Manajemen Risiko pada Proyek Konstruksi. Denpasar: Udayana University Press.

Sucita, I. K. (2011). Identifikasi dan Penanganan Risiko K3 pada Proyek Konstruksi Gedung (Studi Kasus: Proyek Gedung Centro City Residence). Poli Teknologi, 83-92. 